\title{
RESULT OF ULNAR COLLATERAL LIGAMENT RECONSTRUCTION IN POST-TRAUMATIC VALGUS INSTABILITY OF ELBOW
}

\author{
Shouvik Saha1, Soumyadip Dutta², Ranadip Halder ${ }^{3}$, Debojyoti Mukherjee ${ }^{4}$, Dilip Kumar Pal5, Gautam Gupta6, Debasis Mukherjee \\ Abhishek Das ${ }^{8}$
}

1Postgraduate Trainee, Department of Orthopaedics, R. G. Kar Medical College and Hospital, Kolkata.

${ }^{2}$ Assistant Professor, Department of Orthopaedics, R. G. Kar Medical College and Hospital, Kolkata.

3Postgraduate Trainee, Department of Orthopaedics, R. G. Kar Medical College and Hospital, Kolkata.

${ }^{4}$ Assistant Professor, Department of Orthopaedics, R. G. Kar Medical College and Hospital, Kolkata.

5 Professor and HOD, Department of Orthopaedics, R. G. Kar Medical College and Hospital, Kolkata.

${ }^{6}$ Senior Resident, Department of Orthopaedics, R. G. Kar Medical College and Hospital, Kolkata.

${ }^{7}$ Senior Resident, Department of Orthopaedics, R. G. Kar Medical College and Hospital, Kolkata.

sPostgraduate Trainee, Department of Orthopaedics, R. G. Kar Medical College and Hospital, Kolkata.

\section{ABSTRACT}

\section{BACKGROUND}

Ulnar collateral ligament is the major valgus stabiliser of the elbow. Its injury mainly occurs in athletes involving in overhead throwing activity. In general population, it occurs in those doing manual labour with overhead throwing activity.

Our aim is to study the result of MCL reconstruction in traumatic valgus instability of elbow.

\section{MATERIALS AND METHODS}

Inclusion criteria were 1) age $<50$ years, 2) valgus stress test positive, 3) positive moving valgus stress test \& milking manoeuvre. Exclusion criteria were 1) age $>50$ years, 2) positive posterolateral rotatory instability test, 3) positive apprehension in pivot shift manoeuvre. Total 34 patients were studied. Among them, 14 were athletes \& 20 were not. A trial of conservative management was tried in the non-athlete group \& 6 of them responded well. Finally, total 28 patients were operated \& followed up for 2 years.

\section{RESULTS}

There was significant improvement of Mean pre-op MAYO elbow, DASH \& VAS score between pre-op \& 2 years follow-up values both in athlete $\&$ non-athlete groups. All the patients returned to their pre-injury activity level within 1.5 years after surgery.

\section{CONCLUSION}

Isolated MCL injury can occur in manual labourers involving in overhead throwing activity. Conservative treatment can be tried in non-athlete group with good result. Reconstruction of MCL using Gracilis autograft gives good functional outcome \& return to preinjury level of activity in both athlete and non-athlete groups.

\section{KEYWORDS}

Valgus Instability, UCL Reconstruction, Hamstring Autograft, Athlete \& Non-Athlete Populations.

HOW TO CITE THIS ARTICLE: Saha S, Dutta S, Halder R, et al. Result of ulnar collateral ligament reconstruction in post-traumatic valgus instability of elbow. J. Evolution Med. Dent. Sci. 2017;6(22):1750-1753, DOI: 10.14260/Jemds/2017/385

\section{BACKGROUND}

Ulnar collateral ligament (UCL) of the elbow is the major valgus stabiliser of the elbow. It consists of three partsanterior bundle, posterior bundle \& transverse bundle. Among them anterior bundle is the most important valgus stabiliser. ${ }^{1}$ Anterior bundle originates from the anteroinferior portion of medial epicondyle and inserts to sublime tubercle of proximal ulna. The posterior bundle mainly resists the ulnar rotation. Injury to the medial collateral ligament (MCL) occurs most frequently as a result of repetitive microtrauma during overhead throwing activity specially in athletes, 2,3 but it can occur as a single traumatic event. During late cocking, early acceleration phase of throwing valgus force is distributed over elbow, 4 among that $55 \%$ is absorbed by MCL. 5

Financial or Other, Competing Interest: None.

Submission 21-01-2017, Peer Review 04-03-2017,

Acceptance 10-03-2017, Published 16-03-2017.

Corresponding Author:

Dr. Shouvik Saha,

\#93/1 Sonatuli Lane,

Post+Dist. -Hooghly-712103.

E-mail: nicolascage.cage80@gmail.com

DOI: $10.14260 /$ jemds $/ 2017 / 385$ occurring in those populations involving in overhead activities like manual labourers. The aim of our study is to determine the result of reconstruction of MCL in case of traumatic valgus instability of elbow in both athlete \& nonathlete population.

\section{MATERIALS AND METHODS}

The inclusion criteria of our study were 1) age $<50$ years, 2) valgus stress test positive, 3 ) positive moving valgus stress test and milking manoeuvre, 4) isolated MCL tear in MRI. Exclusion criteria were 1) age $>50$ years, 2) positive posterolateral rotatory instability test, 3) positive apprehension in pivot shift manoeuvre. In between 20102016, we chose total 34 patients satisfying the inclusion criteria. Among them, 14 were athletes and rest 20 were not. All non-athletes were either masons or manual labourers especially involving in overhead carrying and throwing heavy objects. All patients presented to us with complaint of medial side elbow pain and difficulty in performing their throwing activity.

Initially all the patients were evaluated clinically and in all of them tenderness was present over medial aspect of elbow joint. Valgus stress test and milking manoeuvre were 
positive. Patients who presented with positive posterolateral rotatory instability test were excluded from the study. Then radiological evaluations were done by doing x-ray \& MRI. In imaging studies, presence of fractures, intra-articular loose bodies \& tear of MCL were evaluated. In all patients, complete tear of MCL was noted with absence of any fracture, loose bodies in the joints. In the non-athlete group, a trial of conservative treatment consisting of rest, forearm and shoulder strengthening exercise, NSAIDs were applied for 4-6 weeks. Among the 20 patients, 6 responded well, rest 14 didn't respond to conservative management and operative reconstruction of MCL was done among them.

\section{Operative Procedure}

Original description of MCL reconstruction was given by Jobe. ${ }^{6}$ He described the procedure using Palmaris longus graft. Then various modifications of Jobe method were described.7,8 In our study, we used Altchek et al ${ }^{8}$ docking technique as the procedure has several benefits like avoidance of obligatory nerve transfer, reduction of number of humeral tunnel and simplification of graft tensioning. In our study, we used gracilis tendon as Palmaris longus tendon may be absent in $15-20 \%$ of population and harvesting gracilis graft has less chance of neurological damage as compared to Palmaris tendon.

In supine posture under general anaesthesia, gracilis graft was harvested.

Incision made over medial aspect of elbow across medial epicondyle to a point $2 \mathrm{~cm}$ beyond sublime tubercle of ulna after application of tourniquet.

Fascia of flexor carpi ulnaris was incised and splitting of underlying ligament was done. Intraoperative laxity of the MCL was observed by valgus stress. Ulnar nerve was protected. Ulnar tunnels were created anterior and posterior to the sublime tubercle maintaining a bony bridge.

Humeral tunnel was created in the anterior half of the medial epicondyle in the anterior position of the existing MCL.

Graft was passed in ulnar tunnel from anterior to posterior and fixed with interference screw.

With the first limb of the graft securely docked in the humerus, elbow was reduced maintaining varus stress. Final length of the graft was measured and non-absorbable suture was placed in a Krackow fashion. That end of the graft was docked with the suture exiting the small superior humeral tunnel.

Final graft tensioning was performed moving the elbow in full range of motion and applying varus stress.

Ulnar nerve transposition was not done. Wound was closed. Tourniquet was removed and elbow was put in back slab at $60^{\circ}$ flexion.

\section{Post-op Regimen}

After 2 weeks, suture removal was done. After 10 days, limb was put in a hinged brace. Motion was allowed between 45$90^{\circ}$. Over the next 3 weeks, motion was gradually advanced to full. Physical therapy programme was started at 6 weeks and gradual strengthening exercise of the shoulder and forearm was started. Valgus stress was avoided. At 12 weeks, strengthening programme became more vigorous and bench pressing with light to moderate weight was allowed. At 4 months, throwing programme was allowed for athletes.
Patients were followed up at 6 weeks, 6 months, 1 year \& 2 years acoording to DASH score, MAYO elbow performance score, range of motion \& VAS score.

\section{RESULT}

Injury to ulnar collateral ligament was first reported by Waris $^{9}$ in 1946. Since then multiple reports ${ }^{3,6}$ have been published mentioning its occurrence in athletes specially in basketball players. ${ }^{10,11}$ In our study, we took 14 athletes \& 20 manual labourers. In the athlete group, conservative treatment was not tried as studies showed conservative treatment in athlete group didn't give satisfactory result. ${ }^{12}$ In our study among the non-athlete group, a conservative treatment was tried and $6(30 \%)$ of them responded well, finally rest $14(70.0 \%)$ of them were operated. In preoperative evaluation, no intra-articular loose bodies were detected, so arthroscopic examination was not performed. In our study, total 14 athlete \& 14 non-athlete patients were operated. The mean age of athlete group was $33.25 \pm 4.27$ years and that of the non-athlete group was $44.00 \pm 4.83$ years. The mean pre-op Mayo elbow score, DASH score, VAS score among the athlete group were $43.75 \pm 4.78,47.82 \pm$ $6.69,5.00 \pm 0.81$ respectively. Post-op 6 weeks, the same scores were $70.00 \pm 4.08,30.12 \pm 6.52,2.75 \pm 0.50$ respectively. At the end of 2 years followup, the values were $98.75 \pm 2.50[(\mathrm{z}$ score 1.84$)$ which was statistically not significant], $52 \pm 1.05$ [(z score 1.82 ) which was statistically not significant] (Wilcoxon signed ranks test), $0.00 \pm .00[\mathrm{z}$ score 1.84] respectively. No patient had postoperative ulnar nerve paresis or infection. All of them had good range of motion of elbow, shoulder joints, etc. All the athletes returned to their pre-injury activity level within 1.5 years. The mean time of return to pre-injury activity level was $1.60 \pm 0.24$ yrs.

Among the non-athlete group, the mean age was $44.00 \pm$ 4.83 years. The mean pre-op Mayo elbow score, DASH score, VAS score among the non-athlete group were $41.25 \pm 6.29$, $46.50 \pm 8.69,5.00 \pm 0.81$ respectively. The 6 weeks post-op scores were $66.25 \pm 4.78,26.75 \pm 4.28,3.00 \pm 0.81$ respectively. At the end of 2 years followup, the values were $98.75 \pm 2.50$ [z score 1.89], $1.20 \pm 1.49$ [z score 1.82], $0.00 \pm$ .00 [z score 1.84$]$ respectively (Wilcoxon signed ranks test). 2 patients had postoperative ulnar nerve paresis in the form of tingling, numbness sensation along the ulnar nerve distribution, which was managed conservatively and complete recovery took place within 6 months. There were no post-op infections. All the patients returned to their preop activity level within 1.3 years. The mean time of return to pre-injury activity level was $1.21 \pm 0.13$ years.

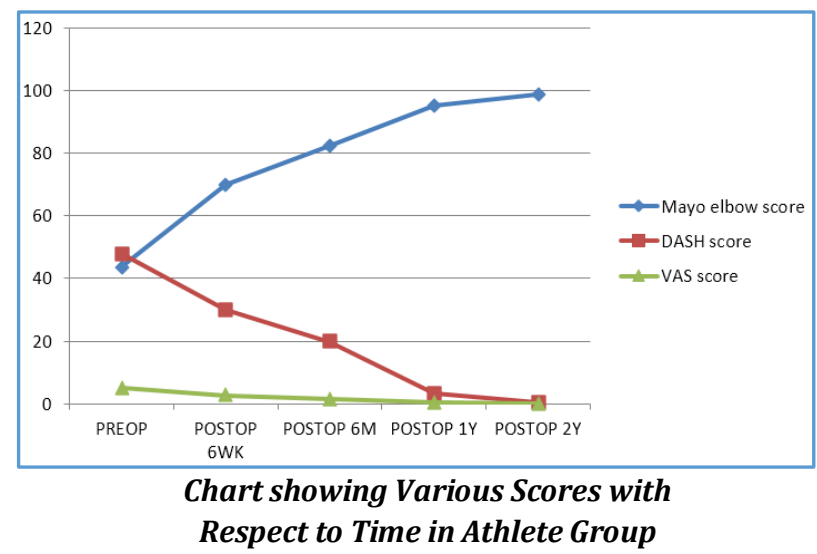




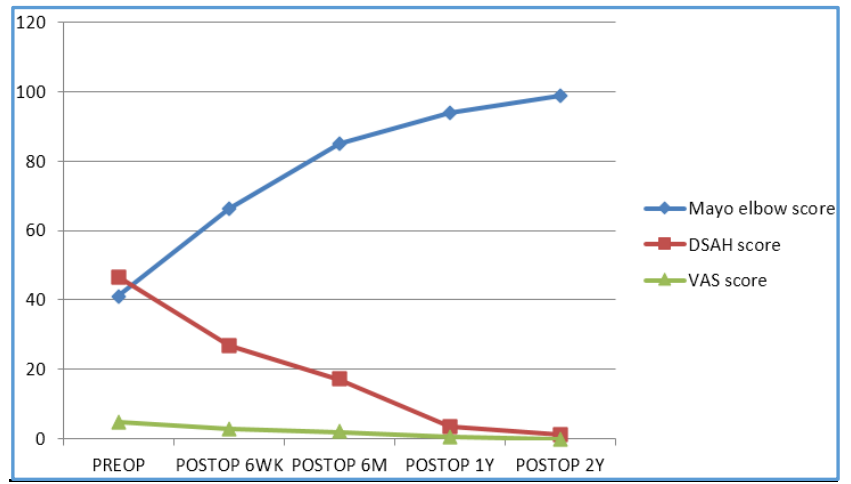

Chart showing Various Scores with

Respect to Time in Non-athlete Group

In our study, all the patients in both the groups showed clinically significant improvement in their functional activities with time. Valgus stress test, milking maneuver ${ }^{13}$ became negative compared to the normal side within 6 months of post-operative period in both the groups.

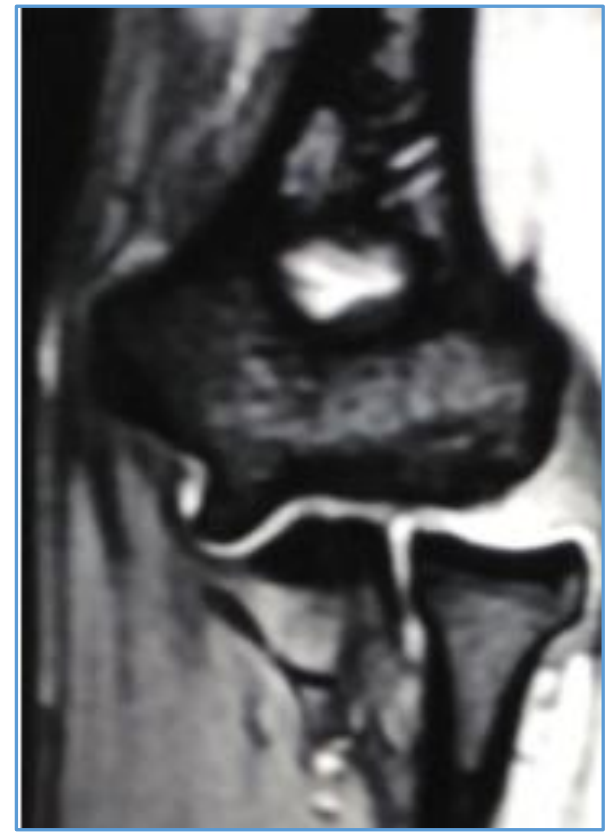

MRI showing MCL Tear

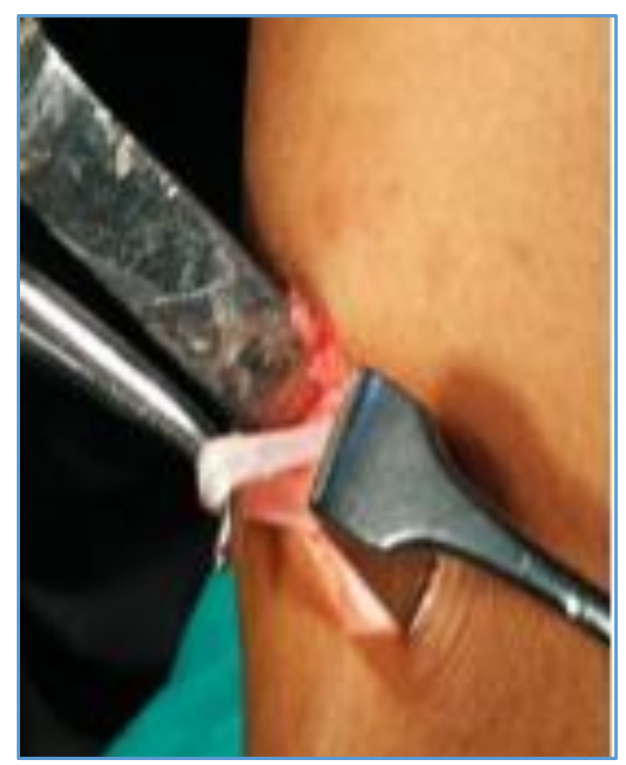

Gracilis Graft Harvesting

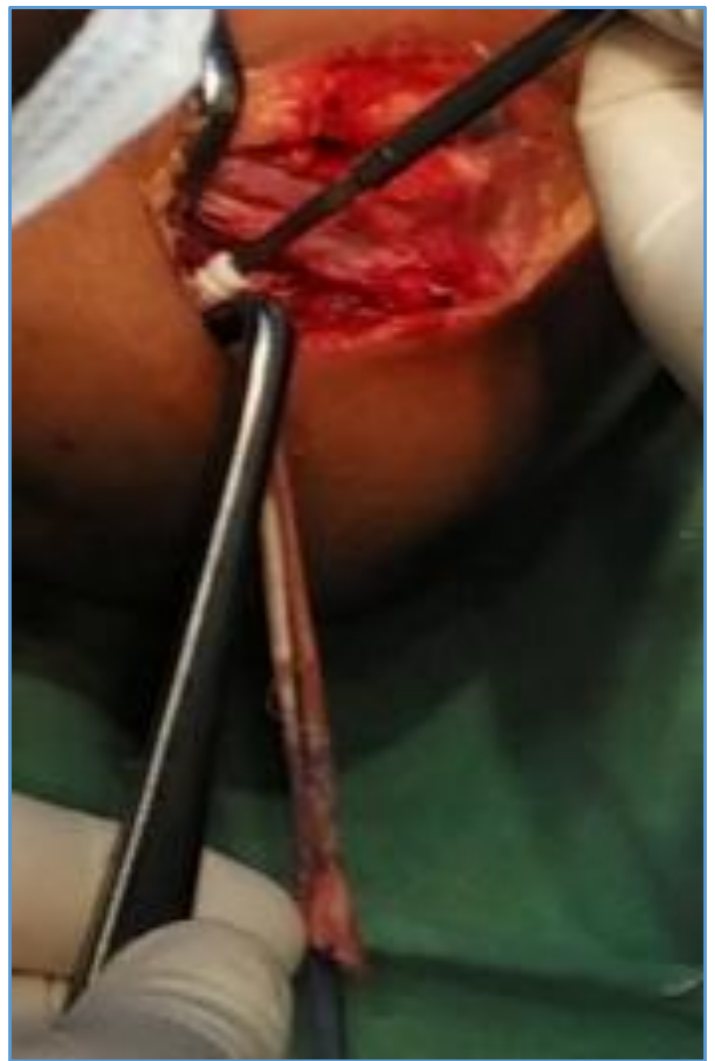

Graft Fixing at Ulnar Tunnel

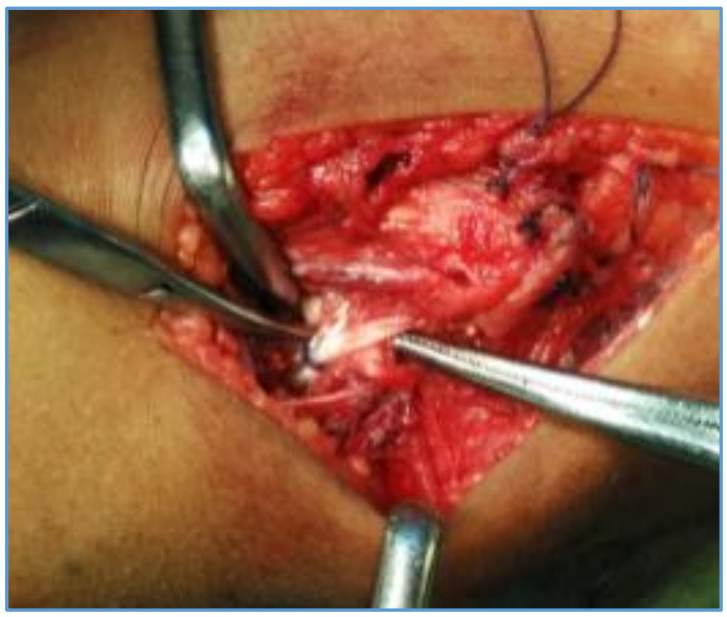

Final Graft Fixing

\section{DISCUSSION}

Repetitive valgus force in throwing athlete leads to tear in ulnar collateral ligament causing a career ending situation among them. The term 'medial elbow stress syndrome' 14 was described as a unifying concept. Thompson et $\mathrm{al}^{15}$ were the first to report on 83 athletes who underwent MCL reconstruction based on a muscle-splitting approach without ulnar nerve transposition. Of these 83 patients, 33 were followed up for 2 years. The surgical results were excellent in $82 \%$ of patients, good in $12 \%$ \& fair in $6 \%$ of patients. These results improved to $93 \%$ excellent when those patients who had a prior procedure were excluded. In our study among the 14 athletes, 6 (42.8\%) were volleyball players and rest 8 (57.1\%) were badminton players. Among the 20 non-athlete patients, all were manual labourers like masons or carriers of heavy objects over their head and delivering the objects by overhead throwing. All the patients presented with medial 
sided elbow pain \& instability of elbow. We diagnosed the MCL tear by clinical (positive valgus stress test \& milking manoeuvre) \& radiological (MRI) examination. Though MCL tear most commonly occurs among overhead throwing athletes,2,3,6 it can occur among the general population especially among manual labourers (like masons) involved in overhead carrying and throwing heavy objects. In our study, $58.8 \%$ of the study populations were not athletic. In nonathlete population, MCL tear occurred at a relatively higher age compared to athlete group. Conservative treatment can be tried in the form of rotator cuff, arm, forearm and core muscle strengthening exercises among the non-athlete group. As in our study, $30.0 \%$ of non-athlete patients responded well in conservative management. Among the athlete group, we had not tried conservative management as studies 11,12 showed unsatisfying results. Classical techniques described ulnar collateral ligament reconstruction using Palmaris longus graft. ${ }^{6}$ But in our study, we used gracilis graft as Palmaris longus may be absent in $15-20 \%$ of general population and taking hamstring graft can minimise the chance of neurological complications. Using gracilis graft had no graft side morbidity and there was no insecurity of nonavailability of the graft. We used Altchek 8 'Docking' technique for reconstruction of MCL as it had several advantages as described above. Only two patients (7.1\%) had postoperative ulnar nerve paresis which recovered completely within 6 months by conservative management. No patient had post-operative infection. All the patients returned to their pre-injury activity level within 1.8 years post-operatively. Younger, non-athlete patients recovered faster compared to older athletes.

\section{CONCLUSION}

Ulnar collateral ligament tear mainly occurs among the overhead throwing athletes, but it also occurs among general populations especially in manual labourers. The major limitation of our study was small sample size and short duration of followup. In-spite of all the limitations, we can conclude that ulnar collateral ligament reconstruction using hamstring autograft brings good functional outcome in both athlete and non-athlete group of population.

\section{REFERENCES}

[1] Callaway GH, Field LD, Deng XH, et al. Biomechanical evaluation of the medial collateral ligament of the elbow. J Bone Joint Surg Am 1997;79(8):1223-31.
[2] Conway JE, Jobe FW, Glousman RE, et al. Medial instability of the elbow in throwing athletes. Treatment by repair or reconstruction of the ulnar collateral ligament. J Bone Joint Surg Am 1992;74(1):67-83.

[3] Dodson CC, Thomas A, Dines JS, et al. Medial ulnar collateral ligament reconstruction of the elbow in throwing athletes. Am J Sports Med 2006;34(12):1926-32.

[4] Fleisig GS, Andrews JR, Dillman CJ, et al. Kinetics of baseball pitching with implications about injury mechanisms. Am J Sports Med 1995;23(2):233-9.

[5] Morrey BF, An KN. Articular and ligamentous contributions to the stability of the elbow joint. Am J Sports Med 1983;11(5):315-9.

[6] Jobe FW, Stark H, Lombardo SJ. Reconstruction of the ulnar collateral ligament in athletes. J Bone Joint Surg Am 1986;68(8):1158-63.

[7] Dines JS, ElAttrache NS, Conway JE, et al. Clinical outcome of the DANE TJ technique to treat ulnar collateral ligament insufficiency of the elbow. Am J Sports Med 2007;35(12):2039-44.

[8] Rohrbough JT, Altchek DW, Hymen J, et al. Medial collateral ligament reconstruction of the elbow using the docking technique. Am J Sports Med 2002;30(4):541-8.

[9] Waris W. Elbow injuries of javelin-throwers. Acta Chir Scand 1946;93(6):563-75.

[10] Cain EL, Dugas JR, Wolf RS, et al. Elbow injuries in throwing athletes: a current concept review. Am J Sports Med 2003;31(4):621-35.

[11] Ciccotti MG, Jobe FW. Medial collateral ligament instability and ulnar neuritis in the athlete's elbow. Inst Course Lect 1999;48:383-92.

[12] Rettig AC, Sherrill C, Snead DS, et al. Nonoperative treatment of ulnar collateral ligament injuries in throwing athletes. Am J Sports Med 2001;29(1):15-7.

[13] David TS. Medial elbow pain in the throwing athlete. Orthopaedics 2003;26(1):94-9.

[14] King JW, Brelsford HJ, Tullos HS. Analysis of the pitching arm of the professional baseball pitcher. Clin Orthop 1969;67:116-23.

[15] Thompson WH, Jobe FW, Yocum LA, et al. Ulnar collateral ligament reconstruction in athletes: musclesplitting approach without transposition of ulnar nerve. J Shoulder Elbow Surg 2001;10(2):152-7. 